\title{
XIX. Silk v. Wire
}

\section{R.H.M. Bosanquet}

To cite this article: R.H.M. Bosanquet (1887) XIX. Silk v. Wire , Philosophical Magazine Series 5, 23:141, 149-150, DOI: $10.1080 / 14786448708627992$

To link to this article: http://dx.doi.org/10.1080/14786448708627992

$$
\text { 曲 Published online: } 29 \text { Apr } 2009 .
$$

$\sqrt{6}$ Submit your article to this journal $₫$

Џll Article views: 2

Q View related articles $\asymp$ 
down, they would form a coating of about 900 feet in thickness above the datum level, which would be the surface, had the matter of the crust been perfectly compressible so that compression would not have corrugated it.

The value obtained for this quantity in my former work was $866^{\circ}$ feet.

Practically, these two numbers do not materially differ; and they show that, if we take into consideration the land and the ocean-basins, the existing inequalities of the surface are greater than can be accounted for by the theory of compression through contraction by cooling of a solid globe, even upon the too highly favourable suppositions made in the present paper. The strictly geological arguments against this theory stand upon their own merits.

The result of the above emendation of the demonstration in my 'Physics of the Earth's Crust' is therefore simply to confirm the arguments I have built upon the less satisfactory calculation given in chapter vi. of that book.

XIX. Silk v. Wire. By R. H. M. Bosanquet.

To the Editors of the Philosophical Magazine and Journal.

Gentlemen,

$N$ a note in the December number of the Philosophical 1 Magazine for 1886, entitled "Silk $v$. Wire, or the 'Ghost" in the Galvanometer," I mentioned reasons for distrusting silk, and alluded amongst other things to the way in which it untwists when stretched. Condensation of expression has its inconveniences, and in the January number for $1887 \mathrm{Mr}$. Gray infers that I used a twisted silk thread, by which, I presume, he means an artificially-twisted silk thread; but that is not so. The thread used was prepared from suspensionsilk supplied by Elliott Brothers. This consists of a small number of fibres more or less aggregated together, and presents no appearance of twist. This is picked to pieces until the substance desired is left. It is then fine enough to be hardly visible.

I abandoned the use of cocoon-fibres and very small needles years ago in consequence of the impossibility of accurately determining the error introduced by the fibre.

I made at one time a great many observations on silk fibres of various descriptions. The phenomenon, to which I alluded in speaking of the untwisting when stretched, may be described as structural twist: it has shown itself as follows, in all silk fibres I have erer examined. 
If a small weight with a pointer is suspended from a silk fibre, and it is brought to rest and left covered under glass, the position will continue slowly to change for some days. This is what I regard as a consequence of structural twist. It and the taking of set combined lead to the phenomenon of the change of zero in galvanometers, leaving the "ghost" out of consideration for the present.

With me, sensitiveness is far from being the first requirement in galvanometers. The elimination of elements of an inconstant character stands first. Now, when we so greatly diminish the moment of the needles as to admit of the properties of the silk suspension causing changes of the zero, which is admittedly the case, we have a demonstration that changes depending on the silk are able to influence the results. The increase in the length of the silk, according to my experience, increases some at least of the irregular effects instead of diminishing them. By the elimination of the silk we can obtain instruments quite sufficiently sensitive for practical purposes, and entirely free from errors which I regard as introduced by an incorrect identification of refinement with accuracy.

Since my former note was written I have wound a pair of coils for the galvanometer in question, consisting of about 500 turns of 16 B.W.G. By employing a cement of shellac varnish thickened with red lead $I$ was able to wind these solid without any frame, and so to get all the thick wire into the same space as before. I thus obtain nearly the same delicacy as with the old silk suspension. The clearness of the indications, as compared with those of the old galvanometer, is evidenced by the facility with which the thermoelectric currents, arising from the binding-screws of the circuit, are identified, a considerable deflection being produced by laying the finger on the brass binding-screw. With the silk such effects were not so easily isolated, movements often continuing even though the circuit was not joined up.

Mr. Gray deprecates going back, "something like half a century," to galvanometers with large needles. I doubt whether the older experimenters realized the advantages of wire suspension. But I have always wondered that so little weight is now attached to the deliberate opinion of Gauss, that accuracy in such measurements is to be best attained by enlarging the dimensions of the apparatus. In this matter I am occasionally tempted to think that the old is better. 